\title{
Enterococcus faecalis Bioflocculant Enhances Recovery of Graphene Oxide from Water
}

\author{
Liang Xü ${ }^{1}$, Renshi Ma ${ }^{2}$, Caiyun Sun ${ }^{1 *}$, Dazhi Sun ${ }^{1 * *}$ \\ ${ }^{1}$ Jilin Institute of Chemical Technology, Jilin, China \\ ${ }^{2}$ Department of Vascular Surgery, First Hospital of Jilin University-Eastern Division, Changchun City, \\ Jilin Province, China
}

Received: 12 September 2017

Accepted: 17 December 2017

\begin{abstract}
Bioflocculation is a promising method of removing GO from the water as it is safe, biodegradable, and non-secondary pollution, but few studies on effective and economic bioflocculant of GO have been reported. Accordingly, this work evaluated flocculation efficiency of an extracellular bioflocculant named MBF-21 produced by Enterococcus faecalis. Optimum culture conditions for bioflocculant production were initial medium $\mathrm{pH}$ of 7 and incubation temperature of $40^{\circ} \mathrm{C}$. The optimum carbon and nitrogen sources for bioflocculant production were glucose and beef extract. Results of Fourier transform infrared (FTIR) indicated the presence of carboxyl, hydroxyl, and amide groups on the MBF-21. The Zeta potential of MBF-21 analysis revealed that MBF-21 was mainly negatively charged. MBF-21 showed a significant ability in flocculation of $\mathrm{GO}$, and flocculation efficiency was over $90 \%$ under neutral, acidic, and alkaline conditions, indicating that flocculation of GO was ion-independent. The conditions for flocculation of GO were optimized by response surface methodology (RSM) and determined to be an $11.57 \mathrm{mg} / \mathrm{L}$ dose and flocculation time of $75 \mathrm{~min}$.
\end{abstract}

Keywords: bioflocculant, enterococcus faecalis, graphene oxide, microbial flocculation, response surface methodology

\section{Introduction}

Graphene oxide (GO) has been widely used in electronics, biosensors, pipes, and semiconductors for its excellent electrochemical properties [1]. In recent years, with the wide use of $\mathrm{GO}$, wastewater containing $\mathrm{GO}$ are increasingly discharged. According to previous studies, GO can negatively impact wastewater microbial communities [2-3] because GO can hinder the essential

*e-mail: 437621315@qq.com

**e-mail: xulianhg518@126.com microbial functions in activated sludge processes [4-5]. Furthermore, the presence of GO in activated sludge may lead to the decline in $\mathrm{BOD}_{5}$ and depress the removal of nitrogen and phosphorus in the biological treatment process [6].

The methods of bioflocculant for treatment of GO in the water are popular for its safety, biodegradability, and non-secondary pollution. Bioflocculant is an extracellular biopolymer derived from the natural secretions of bacteria [7]. As the predominant components of bioflocculant are polysaccharide, glycoprotein, protein, and nucleic acid, bioflocculation is becoming a popular method for water treatment [8]. Although studies have reported 
on the removal of GO from water with bioflocculation, research in this area is still limited [9]. It is well known that influence factors, temperature, and $\mathrm{pH}$ are major factors in controlling the bioflocculation process, whereas bioflocculant dosage and flocculation time need further study before the practical application for the removal of GO by biofloccuant.

Accordingly, the major objectives of this research are to: (1) screen and identify a novel bioflocculant-producing strain from active sludge; (2) study various factors affecting bioflocculant production, including carbon source, nitrogen source, initial $\mathrm{pH}$, and temperature of incubation; (3) evaluate and optimize the effects of temperature, $\mathrm{pH}$, bioflocculant dosage, and flocculation time by response surface methodology; and (4) explore mechanisms of flocculation of GO with bioflocculant.

\section{Material and Methods}

\section{Identifying Bioflocculant-Producing Strains}

The morphological character of the selected strain was observed with a Nikon E100 microscope and the physiological and biochemical characteristics were identified by Bergey's Manual of Systematic Bacteriology. PCR amplification of $16 \mathrm{~S}$ rDNA was identified with Sangon Biotechnology (Shanghai, China Co., Ltd).

\section{Culture Mediums for Bioflocculant Production}

The selected strain was cultivated using nutrient broth containing $5 \mathrm{~g} / \mathrm{L}$ of peptone, $1.5 \mathrm{of} \mathrm{g} / \mathrm{L}$ beef extract, $1.5 \mathrm{~g} / \mathrm{L}$ of yeast extract, and $5 \mathrm{~g} / \mathrm{L}$ of $\mathrm{NaCl}$. PT-1 culture was used as bioflocculant subculture. The composition of the bioflocculant production medium PT-1 were as follows: glucose, $20 \mathrm{~g} / \mathrm{L}$; yeast extract, $0.5 \mathrm{~g} / \mathrm{L}$; urea, $0.5 \mathrm{~g} / \mathrm{L} ; \mathrm{K}_{2} \mathrm{HPO}_{4}, 5 \mathrm{~g} / \mathrm{L} ; \mathrm{KH}_{2} \mathrm{PO}_{4}, 2 \mathrm{~g} / \mathrm{L} ; \mathrm{MgSO}_{4}, 0.2 \mathrm{~g} / \mathrm{L}$; and $\mathrm{NaCl}, 0.1 \mathrm{~g} / \mathrm{L}$. The initial $\mathrm{pH}$ of the medium was adjusted to 7.0-7.2. After sterilization and inoculation, the strains were cultured at $30^{\circ} \mathrm{C}$ in a rotary shaker at $150 \mathrm{rpm}$ for $72 \mathrm{~h}$. Five factors (carbon source, nitrogen source, initial $\mathrm{pH}$, temperature, and incubation period) were investigated for optimizing the culture conditions for the strain Enterococcus faecalis. To determine the effect of the carbon and nitrogen sources on bioflocculant production, glucose was replaced with sucrose, fructose, lactose, starch, and maltose $(20 \mathrm{~g} / \mathrm{L}$ for each type of compounds), respectively, and peptone was replaced with $\left(\mathrm{NH}_{4}\right)_{2} \mathrm{SO}_{4}, \mathrm{NH}_{4} \mathrm{NO}_{3}, \mathrm{NaNO}_{3}$, beef extract, and urea ( $3 \mathrm{mg} / \mathrm{L}$ for each type of compound) separately. Since our preliminary experiments show that the synthesis and growth process of microbial flocculant is synchronized, the compounds added the same quality here, just by changing the flocculation efficiency directly shows the optimal medium for synthesis of flocculant. All the compounds used in our culture are analytically pure. Initially, the $\mathrm{pH}$ of the production medium was adjusted to 2-9. Temperature of the production media was adjusted to $15-50^{\circ} \mathrm{C}$. The effect of the time course of bioflocculant production was investigated between 0 and $96 \mathrm{~h}$. All the analyses were conducted in triplicate.

\section{Preparing MBF-21}

The selected strain was inoculated into a $150-\mathrm{ml}$ flask containing $50 \mathrm{ml} \mathrm{T-1}$ medium. The bioflocculant produced by selected strain was termed MBF-21. MBF-21 was produced by shaking the flask under $30^{\circ} \mathrm{C}$ at $150 \mathrm{rpm}$ for $72 \mathrm{~h}$. Cell-free supernatant was obtained by centrifuging at $7,000 \mathrm{rpm}$ for $30 \mathrm{~min}$. The method of the bioflocculant purification in this study was according to previous studies [10-11]. Two volumes of cold ethanol (at $4^{\circ} \mathrm{C}$ ) were added to $1 \mathrm{~L}$ culture broth. After centrifuging at $8,000 \mathrm{rpm}$ for $30 \mathrm{~min}$, the obtained precipitate was dissolved in $100 \mathrm{ml}$ deionized water by stirring, and adding $50 \mathrm{~mL}$ of $2 \%$ cetylpyridinium chloride (CPC) solution. After $3 \mathrm{~h}$, the precipitate was collected and dissolved in $100 \mathrm{ml}$ of $0.5 \mathrm{M} \mathrm{NaCl}$ solution. Two volumes of cold ethanol were then added to obtain the precipitate, which was washed with ethanol and dissolved in $5 \mathrm{~mL}$ of deionized water and vacuumdried. About $1.2 \mathrm{~g}$ of pure MBF-21 was obtained in $1 \mathrm{~L}$ culture broth.

\section{Batch Experiment of Bioflocculation of GO}

GO was diluted to $60 \mathrm{mg} / \mathrm{L}$ by the addition of distilled water for stock solution. The effects of flocculation conditions (temperature, $\mathrm{pH}$, flocculation time, and bioflocculant dosage) were studied. The $\mathrm{pH}$ was adjusted to approximately $3.0-11.0$ by $0.1 \mathrm{M} \mathrm{HCl}$ and $0.1 \mathrm{M} \mathrm{NaOH}$. Likewise, the effects of temperature were incubated at desired temperatures.

Table 1. Independent variables and their levels in the experimental design.

\begin{tabular}{|c|c|c|c|c|c|c|}
\hline \multirow{2}{*}{ Independent variables } & \multirow{2}{*}{ Symbols } & \multicolumn{5}{|c|}{ Code levels } \\
\cline { 3 - 7 } & & -2 & -1 & 0 & +1 & +2 \\
\hline Temperature $\left({ }^{\circ} \mathrm{C}\right)$ & $A$ & 0 & 10 & 20 & 30 & 40 \\
\hline $\mathrm{pH}$ & $B$ & 3 & 5 & 7 & 9 & 11 \\
\hline Bioflocculant dosage (mg/L) & $C$ & 0 & 4 & 8 & 12 & 16 \\
\hline Flocculation time (min) & $D$ & 0 & 25 & 50 & 75 & 100 \\
\hline
\end{tabular}


After setting up of fixed parameters, tubes containing the mixture of GO solution and MBF-21 were shaken in an orbital shaker (Model-HZQ-X100, HDL APPARATUS Ltd., China) and stirred at a constant speed of $250 \mathrm{rpm}$. The initial GO concentration was determined under optical density of $290 \mathrm{~nm}\left(\mathrm{OD}_{290}\right)$ by a UV-VIS Spectrophotometer (Model-T6, PGENERAL Ltd., China). The optical density of the supernatant was determined at half height of the clarified culture. Culture broth without bioflocculant was used as control. Flocculation efficiency of GO was calculated by Equation (1) [12-16]:

$$
\text { Flocculation Efficiency }(\%)=(A-B) / A \times 100
$$

...where $A$ is $\mathrm{OD}_{290}$ value of sample and $B$ is $\mathrm{OD}_{290}$ value of control.

\section{Optimizing Flocculation of GO with MBF-21}

Design Expert Software (version 8.0) was used for statistical design of the experiments and data analysis. In this study, the central composite design (CCD) and response surface methodology (RSM) were applied to optimize the four factors: MBF-21 dosage, temperature, flocculation time, and $\mathrm{pH}$. The narrower ranges of MBF-21 dosage, temperature, flocculation time, and $\mathrm{pH}$ were determined prior to designing the experimental runs. The narrower ranges of MBF-21 dosage, flocculation time, temperature, and $\mathrm{pH}$ were chosen: 0-16 $\mathrm{mg} / \mathrm{L}, 0-100 \mathrm{~min}, 0-40^{\circ} \mathrm{C}$, and 3-11, respectively. The 4 independent factors with 5 different levels $(-2,-1,0,+1,+2)$ were investigated and the experimental designs are shown in Table. 1.

The response variable (y) for flocculation efficiency was fitted by a second-order model and calculated by the following quadratic polynomial equation (2):

$$
\begin{gathered}
\text { Flocculation Efficiency }=+71.53-4.66 * A \\
+0.43 * B+22.49 * C+18.06 * D+2.67 * A \\
* B+0.86 * A * C-2.95 * A * D-0.98 * \\
B * C-0.96 * B * D+8.96 * C * D-5.74 \\
* A^{2}-1.68 * B^{2}-9.73 * C^{2}-9.94 * D^{2}
\end{gathered}
$$

...where flocculation efficiency is the predicted response and the independent factors $A, B, C$, and $D$ are temperature, $\mathrm{pH}, \mathrm{MBF}-21$ dosage, and flocculation time, respectively. All the analyses were conducted in triplicate. The error bars are marked in all the figures except the central composite design (CCD), and response surface methodology (RSM) data analysis. The data in the response surface are fitted with the average of three sets of repeated data and they were analyzed by ANOVA.

\section{Analytical Methods}

Zeta potential measurement of MBF-21 was conducted by Zeta potential analyzer (Malvern nano ZS, Malvern,
England). A Fourier-transform infrared spectrometer (Nicolet 6700, ThermoFisher, USA) was used for space atmospheric component detection of MBF-21. A scanning electron microscope (XL30-ESEM, FEI, USA) was applied to detect flocculated GO.

\section{Results and Discussion}

Screen and Identification of Bioflocculant-Producing Strain

Strains were isolated from activated sludge of a Second Wastewater Treatment Plant, Changchun, China. Seven strains with flocculation efficiency greater than $80 \%$ for $30 \mathrm{mg} / \mathrm{L}$ GO suspension were screened and identified. Among the 7 strains, strain N-21 was rodshaped, gram-positive, unmotile, catalase-negative, arginine dihydrolase-positive, and oxidase-negative, and produced acids from glucose under anaerobic conditions. The 16S rDNA was sequenced after polymerase chain reaction (PCR) amplification and compared with sequences deposited in databases. A total of 1,501 bp of $16 \mathrm{~S}$ rDNA of N-21 was determined. The highest level of $16 \mathrm{~S}$ rDNA sequence is $99.9 \%$ - similar to Enterococcus faecalis (NCBI EU285587).
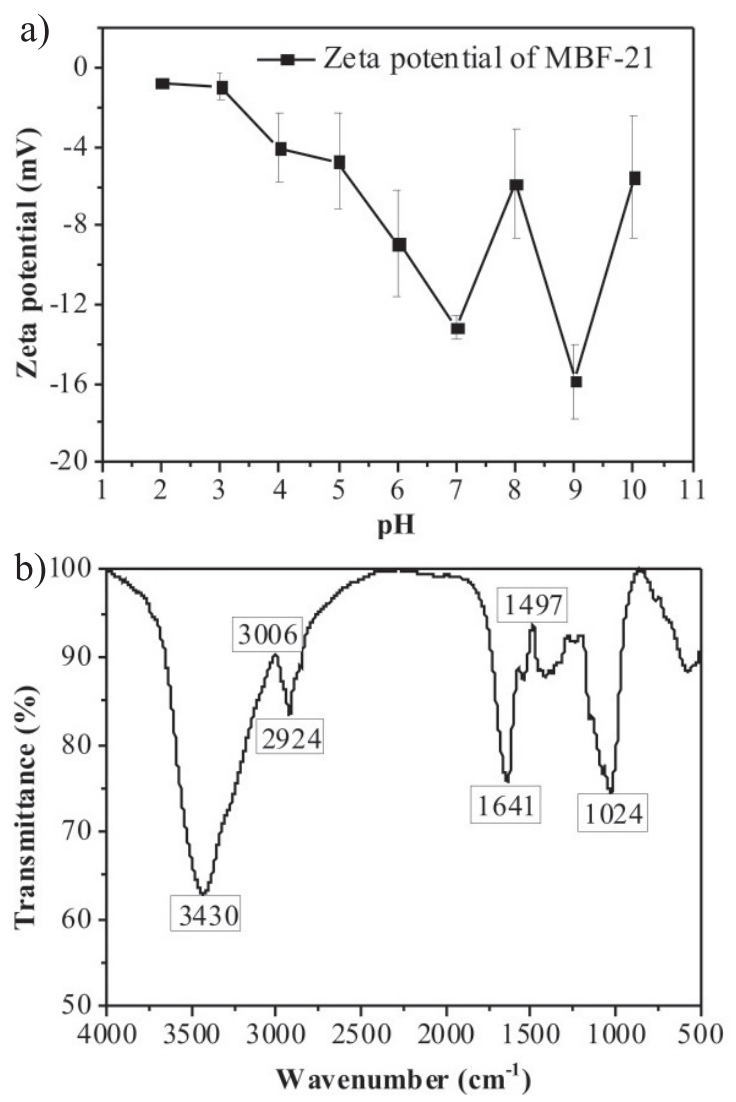

Fig. 1. Zeta potential of MBF-21 and its Fourier-transform infrared spectrometer analysis: a) Zeta potential of purified MBF-21, b) infrared radiation (IR) spectrum investigated of purified MBF-21. 
Zeta Potential of MBF-21 and its Fourier-Fransform Infrared Spectrometer Analysis

The microbial flocculant of Enterococcus faecalis, termed MBF-21, was purified and its infrared radiation (IR) spectrum was investigated. The IR spectrum of the purified MBF-21 exhibited an amide band broad hydroxyl stretching peak at $3,430 \mathrm{~cm}^{-1}$, and a carboxyl band at 1,641-1,497 $\mathrm{cm}^{-1}$ as presented in Fig. 1a). The adsorption peak at $3,006-2,924 \mathrm{~cm}^{-1}$ indicated the $\mathrm{C}-\mathrm{H}$ stretching vibration. Strong adsorption peaks present in the range $1,024 \mathrm{~cm}^{-1}$ are typical characteristics for sugar derivatives [17]. Zeta potential measurement of MBF-21, (Fig. 1b), indicated that MBF-21 was negatively charged in both alkaline and acidic solutions.

\section{Effects of Carbon and Nitrogen and Sources on MBF-21 Production}

The effects of various carbon sources on the production of MBF-21 were evaluated. As shown in Fig. 2a), lactose, fructose, and glucose were favorable carbon sources for both the production of MBF-21 and cell growth. The glucose as carbon source was the cheapest and achieved the highest flocculation rate
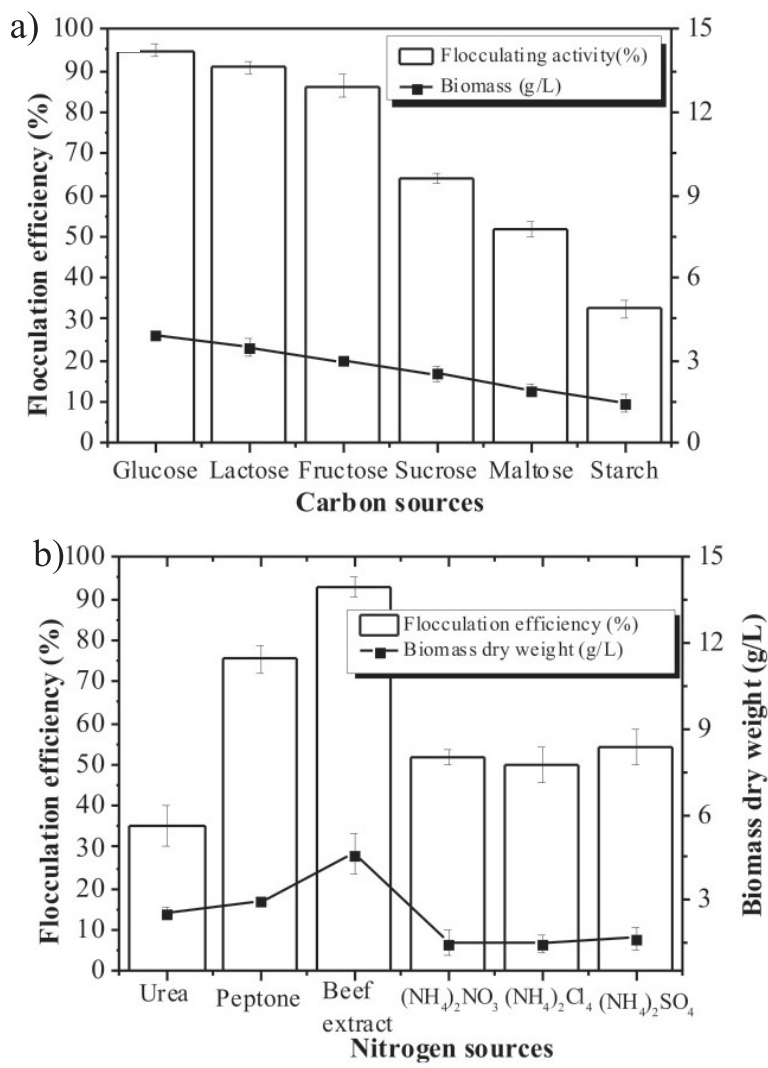

Fig. 2. Effect of carbon sources and nitrogen sources on Enterococcus faecalis and production of MBF-21: a) effect of carbon sources on MBF-21 production with peptone used in the medium as nitrogen source and $b$ ) the effect of nitrogen sources on MBF-21 production with glucose used in the medium as carbon resource. of $94.7 \%$, thus the glucose was selected as the carbon source in the flocculation of GO. Glucose was also reported as the favorable carbon source in the production of bioflocculant [18]. Fig. 2b) illustrates the effects of different nitrogen sources on the production of MBF-21, when glucose was used as the carbon source. The results showed that all inorganic nitrogen sources led to poor production of MBF-21 and cell growth, and the organic nitrogen sources were evidently better than inorganic nitrogen sources for MBF-21 production. Beef extract was therefore selected as the nitrogen source in the following experiments. Organic nitrogen sources were also reported as the favorable carbon sources in the production of bioflocculant [19].

\section{Effect of Initial $\mathrm{pH}$ and Temperature on MBF-21 Production}

The effect of the initial $\mathrm{pH}$ in fermentation runs on the cell growth and flocculating activity were examined (Fig. 3a). The initial $\mathrm{pH}$ of the culture medium could affect the electrification state of strain cell and redox potential, and enzymatic reaction of bioflocculantproducing strains. The highest flocculating rate was recorded between 6 and 7, and the biomass (dry weight)
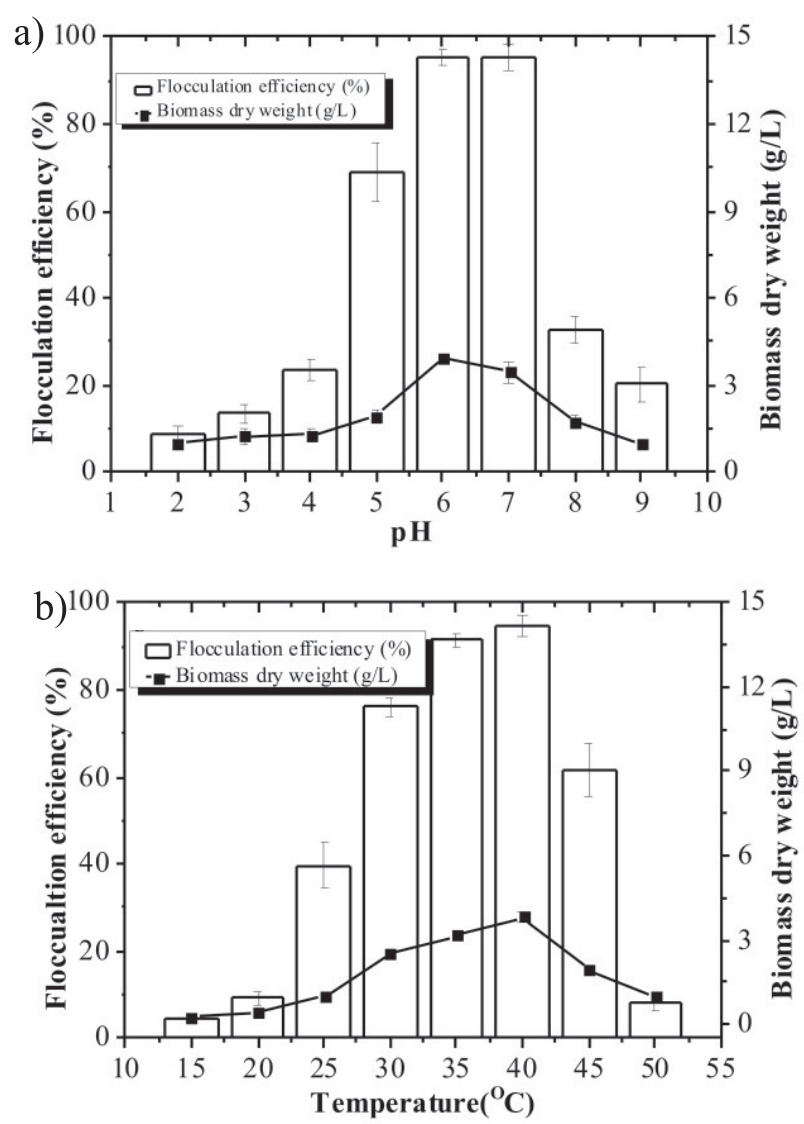

Fig. 3. Effect of initial $\mathrm{pH}$ and temperature on Enterococcus faecalis and production of MBF-21: a) effect of initial $\mathrm{pH}$ on MBF-21 production and b) effect of temperature on MBF-21 production. 


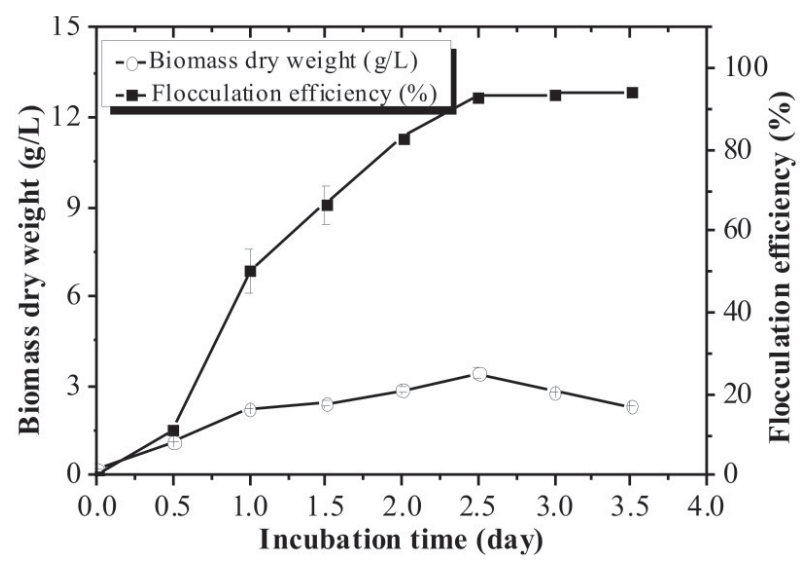

Fig. 4. Time course of the production of MBF-21; rrror bars indicate standard deviation of triplicate experiments.

was highest at $\mathrm{pH}$ 6. Fig. 3b) illustrates the effect of culture temperature on fermentation runs. The cultures grown at $35^{\circ} \mathrm{C}$ and above the culture temperature showed a rise in flocculating rate, reaching $94.77 \%$ at $40^{\circ} \mathrm{C}$.

\section{Time Course of the Production of MBF-21}

The growth curve of Enterococcus faecalis and the flocculating activity of the culture broth are shown in Fig. 4. During fermentation, the production of MBF-21 paralleled the growth of the biomass. The flocculating activity in different culture supernatants from early stationary cultures was the highest $(93.28 \%$ at $60 \mathrm{~h})$. The same phenomenon was reported in the cultivation of Aspergillus parasiticus [18], Bacillus mucilaginosus [20], and Citrobacter sp. TKF04 [21]. At late stationary phase, the flocculating activity stopped increasing, which may have been due to the activities of enzymes that were up to maximum value [22]. After 72 h, Enterococcus faecalis reached its early dead phase, and consequently the flocculating activity of MBF-21 remained the same.

\section{Optimizing Flocculation of GO using RSM Effects of MBF-21 Dosage, Temperature, $\mathrm{pH}$, and Flocculation Time on Flocculation Efficiency}

The experiment assignment and the collected response data are shown in Table 2. As shown in Table 3, the linear terms for flocculant dosage (C) and flocculation time (D) had significant effects on flocculation efficiency ( $\mathrm{F}$ value $<0.05$ ), but temperature (A) and $\mathrm{pH}$ (B) had no significant effects on efficiency. The relationship between temperature in the range of $10-40^{\circ} \mathrm{C}$ and flocculation efficiency was studied. Fig. 5 shows that the highest flocculation efficiency was achieved at $17.58^{\circ} \mathrm{C}$. With the temperature raising from 10 to $17.58^{\circ} \mathrm{C}$, flocculation efficiency increased from $69.87 \%$ to $71.81 \%$ and decreased to $60.72 \%$, with temperature rising to $30^{\circ} \mathrm{C}$.
Table 2. Experimental design and results of the central composite design.

\begin{tabular}{|c|c|c|c|c|c|}
\hline \multirow{2}{*}{ Run } & \multicolumn{4}{|c|}{ Variables } & \multirow{2}{*}{${ }^{a} \mathrm{FA}(\%)$} \\
\hline & ${ }^{\mathrm{d}} \mathrm{T}\left({ }^{\circ} \mathrm{C}\right)$ & $\mathrm{pH}$ & ${ }^{\mathrm{b}} \mathrm{BS}(\mathrm{mg})$ & ${ }^{\mathrm{c}} \mathrm{FT}(\mathrm{min})$ & \\
\hline 1 & 20.00 & 11.00 & 8.00 & 50.00 & 86.58 \\
\hline 2 & 40.00 & 7.00 & 8.00 & 50.00 & 52.15 \\
\hline 3 & 20.00 & 7.00 & 8.00 & 50.00 & 70.94 \\
\hline 4 & 20.00 & 3.00 & 8.00 & 50.00 & 76.07 \\
\hline 5 & 20.00 & 7.00 & 8.00 & 50.00 & 70.32 \\
\hline 6 & 10.00 & 9.00 & 4.00 & 25.00 & 12.26 \\
\hline 7 & 10.00 & 9.00 & 12.00 & 25.00 & 22.25 \\
\hline 8 & 20.00 & 7.00 & 16.00 & 50.00 & 98.22 \\
\hline 9 & 30.00 & 9.00 & 12.00 & 25.00 & 43.83 \\
\hline 10 & 10.00 & 9.00 & 12.00 & 75.00 & 84.96 \\
\hline 11 & 30.00 & 9.00 & 12.00 & 75.00 & 73.02 \\
\hline 12 & 20.00 & 7.00 & 8.00 & 50.00 & 72.72 \\
\hline 13 & 10.00 & 5.00 & 12.00 & 75.00 & 93.35 \\
\hline 14 & 10.00 & 9.00 & 4.00 & 75.00 & 26.95 \\
\hline 15 & 0.00 & 7.00 & 8.00 & 50.00 & 78.02 \\
\hline 16 & 20.00 & 7.00 & 8.00 & 50.00 & 72.14 \\
\hline 17 & 10.00 & 5.00 & 4.00 & 75.00 & 26.6 \\
\hline 18 & 20.00 & 7.00 & 0.00 & 50.00 & 0.07 \\
\hline 19 & 30.00 & 5.00 & 4.00 & 75.00 & 16.13 \\
\hline 20 & 10.00 & 5.00 & 4.00 & 25.00 & 11.5 \\
\hline 21 & 10.00 & 5.00 & 12.00 & 25.00 & 41.62 \\
\hline 22 & 30.00 & 5.00 & 4.00 & 25.00 & 3.36 \\
\hline 23 & 30.00 & 5.00 & 12.00 & 25.00 & 26.78 \\
\hline 24 & 20.00 & 7.00 & 8.00 & 0.00 & 0.20 \\
\hline 25 & 20.00 & 7.00 & 8.00 & 50.00 & 71.55 \\
\hline 26 & 30.00 & 5.00 & 12.00 & 75.00 & 75.44 \\
\hline 27 & 20.00 & 7.00 & 8.00 & 50.00 & 71.52 \\
\hline 28 & 30.00 & 9.00 & 4.00 & 25.00 & 7.29 \\
\hline 29 & 30.00 & 9.00 & 4.00 & 75.00 & 13.62 \\
\hline 30 & 20.00 & 7.00 & 8.00 & 100.00 & 96.38 \\
\hline
\end{tabular}

${ }^{\text {a}}$ Flocculational activity

${ }^{\mathrm{b} B i o f l o c c u l a n t ~ s i z e}$

'Flocculation time

dTemperature

Table 3 and Fig. 5 (above) show that the influence of $\mathrm{pH}$ on flocculation was not significant, and that flocculation efficiency just increased by $1 \%$, with $\mathrm{pH}$ raising from 5 to 9. As shown in Figure 1 (above), Zeta potential measurement of MBF-21 illustrated that MBF-21 was mainly negatively charged in alkaline 
Table 3. ANOVA analysis for responses Y (flocculation efficiency, \%).

\begin{tabular}{|c|c|c|c|c|c|}
\hline Source & Sum of squares & DF & Mean square & F value & P Value \\
\hline Model & 27065.89 & 14 & 1933.28 & 7.03 & 0.0003 \\
\hline C-Flo dosage & 12142.80 & 1 & 12142.80 & 44.13 & $<0.0001$ \\
\hline D-Flo time & 7831.54 & 1 & 7831.54 & 28.46 & $<0.0001$ \\
\hline $\mathrm{CD}$ & 1285.22 & 1 & 1285.22 & 4.67 & 0.0473 \\
\hline $\mathrm{C}^{\wedge} 2$ & 2594.63 & 1 & 2594.63 & 9.43 & 0.0078 \\
\hline $\mathrm{D}^{\wedge} 2$ & 2709.93 & 1 & 2709.93 & 9.85 & 0.0068 \\
\hline Residual & 4127.21 & 15 & 275.15 & & \\
\hline Lack of Fit & 4123.61 & 10 & 412.36 & 572.58 & $<0.0001$ \\
\hline Pure Error & 3.60 & 5 & 0.72 & & \\
\hline R-Squared & 0.8677 & & & & \\
\hline Adj R-Squared & 0.7442 & & & & \\
\hline Adeq Precision & 9.996 & & & & \\
\hline
\end{tabular}

and acidic conditions. GO has been reported to have different electrical states at different $\mathrm{pH}$ - positively charged in acidic conditions ( $\mathrm{pH}$ below 4 ) and negatively
4) $[23-24]$. So it could be concluded that electrostatic repulsion effect was not the main factor affecting flocculation efficiency. a)

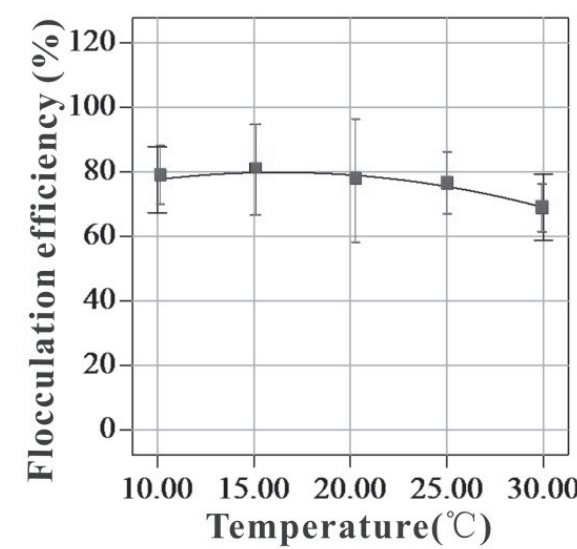

c)

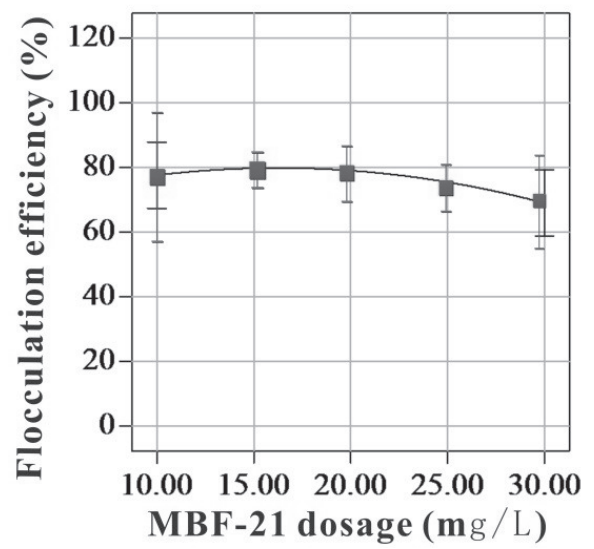

b)

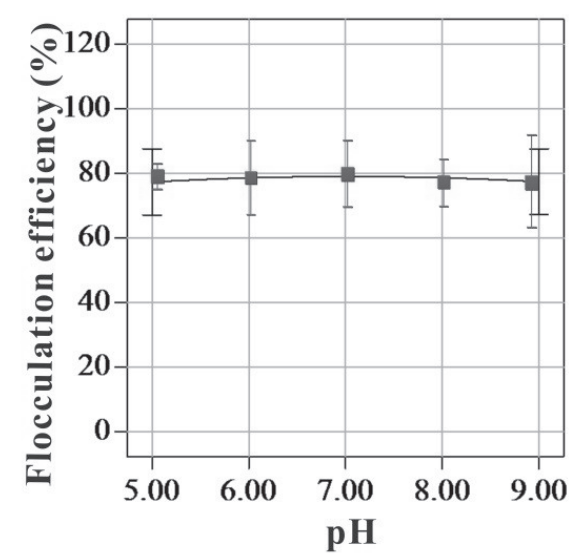

d)

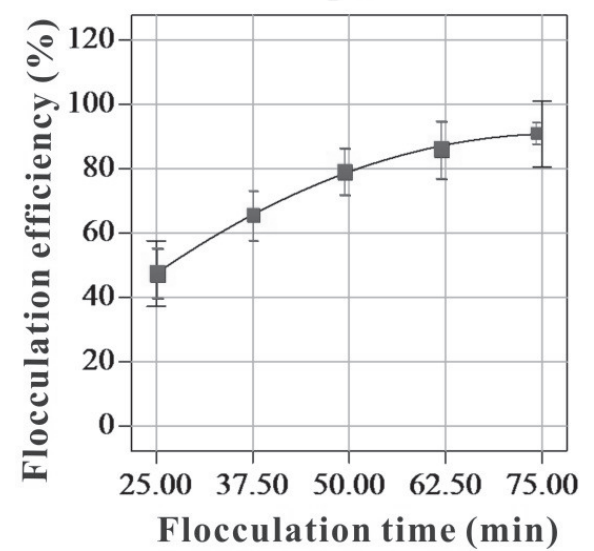

charged in neutral and alkaline conditions $(\mathrm{pH}$ above

Fig. 5. Effect of 4 single variables on removal efficiency, including: a) temperature, b) $\mathrm{pH}$, c) MBF-21 dosage (G value was $\left.0 \mathrm{~s}^{-1}\right)$, and d) flocculation time; $\square$ is verified GO flocculation efficiency under selected conditions. 

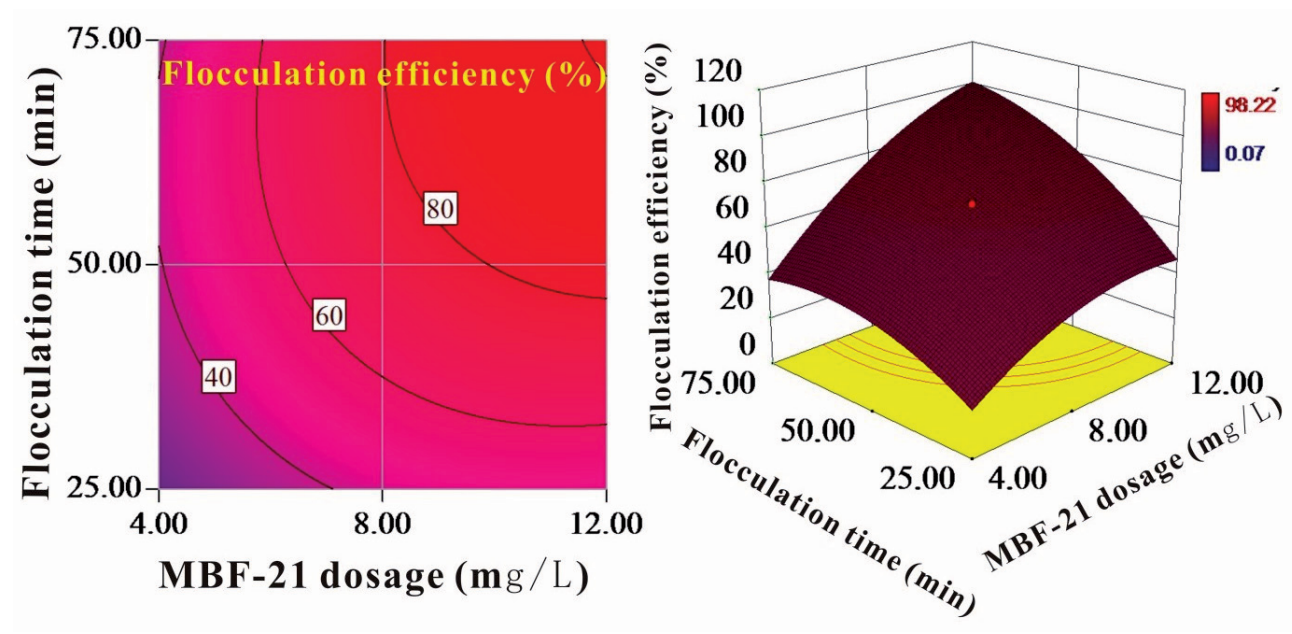

Fig. 6. Surface responses and contour plots showing interactive effect of selected variables on flocculation efficiency (grey spot on the response surface is the best point).

\section{Interaction between Flocculation Time and MBF-21 Dosage on Flocculation Efficiency}

Table 3 shows that flocculation time (C) and MBF-21 dosage (D) were significant impact factors on flocculation efficiency. By changing the other two variables within their experimental ranges and keeping other variable values at middle levels, RSM provided the response surfaces and the contour plots for studying the interactions between the parameters and flocculation efficiency. As shown in Fig. 5 (above), at fixed $\mathrm{pH}$ and temperature, flocculation efficiency increased from $38.91 \%$ to $83.46 \%$ with the rise of dosage from 4 to $12 \mathrm{mg} / \mathrm{L}$. At a fixed MBF-21 dosage of $8 \mathrm{mg} / \mathrm{L}$, flocculation efficiency increased from $43.48 \%$ to $79.45 \%$ with time extension from 25 to $75 \mathrm{~min}$. Lower dosage of $12 \mathrm{mg} / \mathrm{L}$ induced higher efficiency of over $80 \%$. MBF-21 as a long-chain biopolymer performs bridging between $\mathrm{GO}$ particles as shown in Fig. 7b. When MBF-21 is insufficient, the bridging phenomena do not

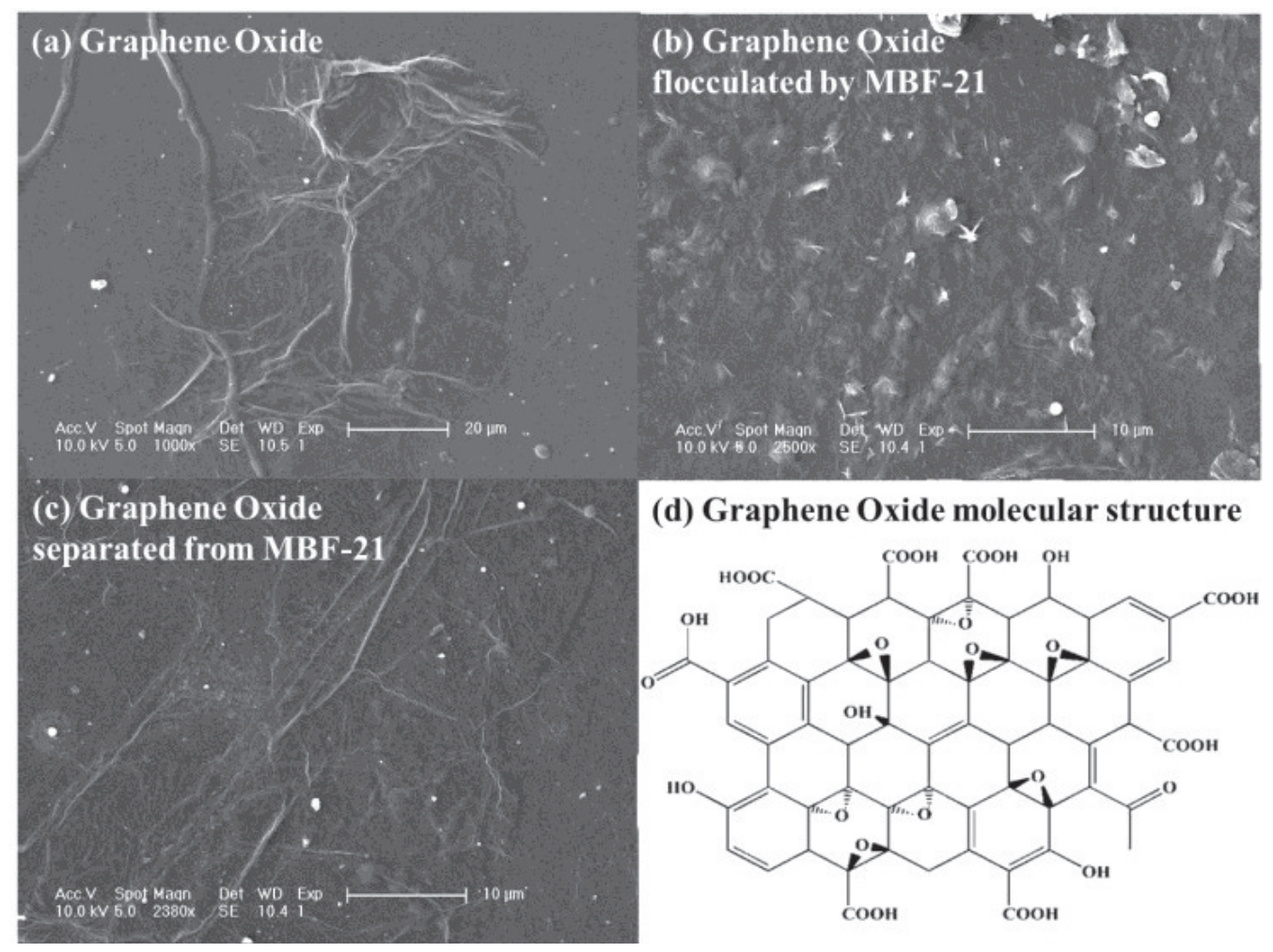

Fig. 7. a) Scanning electron microscope of graphene oxide, b) scanning electron microscope of graphene oxide flocculated by MBF-21, c) scanning electron microscope of graphene oxide separated from MBF-21, and d) molecular structure of GO. 
Table 4. Verification experiments at optimum conditions.

\begin{tabular}{|c|c|c|c|c|c|c|c|}
\hline \multirow{2}{*}{ No. } & \multicolumn{4}{|c|}{ Variables } & \multicolumn{3}{|c|}{${ }^{\mathrm{h}} \mathrm{EF}(\%)$} \\
\cline { 2 - 8 } & ${ }^{\mathrm{a}} \mathrm{T}$ & $\mathrm{pH}$ & $\begin{array}{c}{ }^{\mathrm{b}} \mathrm{FT} \\
(\mathrm{min})\end{array}$ & $\begin{array}{c}{ }^{\mathrm{c}} \mathrm{BS} \\
(\mathrm{mg})\end{array}$ & ${ }^{\mathrm{d}} \mathrm{PV}$ & ${ }^{\mathrm{e}} \mathrm{OV}$ & ${ }^{\mathrm{f}} \mathrm{SD}$ \\
\hline 1 & 25 & 7 & 75 & 11.57 & 95.12 & 93.85 & \pm 0.90 \\
\hline 2 & 20 & 7 & 75 & 11.57 & 99.98 & 97.68 & \pm 1.63 \\
\hline 3 & 20 & 6 & 70 & 11.57 & 100.26 & 98.12 & \pm 1.51 \\
\hline 4 & 25 & 6.5 & 70 & 11.57 & 93.65 & 94.34 & \pm 0.49 \\
\hline 5 & 15 & 8 & 70 & 11.57 & 98.38 & 97.19 & \pm 0.84 \\
\hline
\end{tabular}

${ }^{\text {aTemperature }}$

${ }^{b}$ Flocculation time

'Bioflocculant size

${ }^{\text {dPredicted values }}$

${ }^{\mathrm{e}}$ Observed values

fStandard deviation

hFlocculation efficiency

effectively form. Hummers chemical reduction method is considered to be one of the most efficient, economical, and highly efficient methods for synthesizing graphene. As intermediates in the preparation of graphene with Hummers method, GO still maintains a layered structure of graphite, whose containing groups include carboxyl, hydroxyl, epoxy, etc. (Figs 7a, d). These oxygen functional groups make GO have good dispersibility in water. The obtained GO with recovery methods used in this study maintained consistent water solubility and physical properties (Figure 7c).

GO contains abundant oxygen-containing functional groups on its large surface, such as hydroxyl, carboxyl, and epoxy groups, which makes it extremely hydrophilic in aqueous environments (Fig. 7d). For this reason, the change of $\mathrm{pH}$ cannot change the electrostatic adsorption in the flocculation process. And for the same reason, $\mathrm{pH}$ was not a significant factor on flocculation efficiency as shown in Fig. 5b). In the flocculation process, net trapping is the main factor in the flocculation mechanism as shown in Fig. 7b) [25-26].

\section{ANOVA Analysis and Certification for Response Surface Quadratic Model}

The experimental data of flocculation efficiency were analyzed by ANOVA. All the factors followed secondorder effects, yielding a quadratic model for flocculation efficiency. The significance of each model term was determined by $\mathrm{p}$-values (probability). A p-value less than 0.05 indicates that the model term is important and the insignificant terms ( $p$-value $>0.05$ ) are removed from final expression of the model [27]. In order to bind the response for $\mathrm{Y}$ (removal efficiency) to $100 \%$, LOGIT transformation was used with upper limit as 100. The model, in terms of the coded factors of the flocculation process, was expressed as Equation (2). This model could adequately describe the response based on the p-value $<0.0001$, which is far less than 0.05 .
Adequate precision evaluates the ratios of signal and noise ratio and a ratio greater than 4 is desirable [28]. The ratio was 9.996, demonstrating that this model could precisely describe the process (Table 3). Furthermore, the lack of fit value was insignificant relative to pure error as the p-value was less than 0.05 . The value of correlation coefficient $\left(\mathrm{R}^{2}\right)$ obtained in the present study was 0.884 , which was close to $\mathrm{R}^{2}$ adj (0.74), indicating good agreement between the predicted and observed values of the experiments [29]. Therefore, it was a suitable model to predict flocculation efficiency of GO. Our study showed that temperature (A) and $\mathrm{pH}(\mathrm{B})$ were not significant factors on flocculation efficiency (Figs $5 \mathrm{a}$ and $\mathrm{b}$ ). Their p-value was larger than 0.05 (data not shown in Table 3). At the same time, ANOVA analysis with the response surface quadratic model also proved that flocculation efficiency does not change with the change of these 2 factors viz temperature (A) and $\mathrm{pH}(\mathrm{B})$, that $\mathrm{p}$-value was less than 0.05 (Table 3). For these reasons, we chose the most conventional condition viz $\mathrm{pH}$ 6.5-8 and temperature $15-25^{\circ} \mathrm{C}$ in the optimized experimental conditions [30]. According to the experimental results, the main factors affecting flocculation efficiency are flocculant dosage (C) and flocculation time (D).

The optimization of the operating conditions were conducted by the quadratic models of the experimental design [31-36]. In order to maximize flocculation efficiency and determine the effects of the flocculation process of GO, 5 optimum solutions labelled 1-5 provided by the models were selected and verified under selected optimum conditions. Table 4 illustrates that all the selected optimum solutions had desired prediction of flocculation efficiency with the maximum experimental data. By triplicates of the experiments, the validated experimental results of flocculation efficiency and the values predicted by the models are shown in Table 4 . The observed values of flocculation efficiency ranging from $93.85 \%$ to $98.12 \%$ were desirable. The deviations between the experimental and predicted values ranged from $0.49 \%$ to $1.63 \%$. Therefore, the model was considered to fit the experimental data very well.

\section{Conclusions}

The results showed that Enterococcus faecalis produced bioflocculant that had never before been reported. The most preferred carbon and nitrogen sources for strain Enterococcus faecalis were glucose and beef extract, respectively. Fourier transform infrared (FTIR) indicated the presence of the carboxyl, hydroxyl, and $\mathrm{C}-\mathrm{H}$ groups, which are typical characteristics for sugar moieties. The Zeta potential of MBF-21 analysis revealed that MBF-21 was mainly negatively charged. MBF-21 showed a high flocculation efficiency of GO without cations. Flocculation conditions of GO were optimized using response surface methodology. The results showed that highest flocculation efficiency over $98 \%$ occurred under optimistic conditions in which the dosage was 
$11.57 \mathrm{mg} / \mathrm{L}$ and flocculation time was 75 minutes. While temperature and $\mathrm{pH}$ are not significant factors in the flocculation process of GO, it was suggested that MBF-21 possessed excellent ability in flocculating GO from water.

\section{Acknowledgements}

This work was supported by the National Natural Science Foundation of China (No. 51708248), the " $13^{\text {th }}$ Five-Year" Planning Project of Education Department of Jilin Province (2015, No. 438), and as a Major Project of Jilin Institute of Chemical Technology (No. 2015004).

\section{References}

1. LIU L., GAO B., WU L., MORALES V.L., YANG L.Y., ZHOU Z.H., WANG H. Deposition and transport of graphene oxide in saturated and unsaturated porous media. Chemical Engineering Journal, 229, 444, 2013.

2. LIU S., ZENG T.H., HOFMANN M., BURCOMBE E., WEI J., JIANG R., KONG J., CHEN Y. Antibacterial activity of graphite, graphite oxide, graphene oxide, and reduced graphene oxide: Membrane and oxidative stress. ACS Nano, 5, 6971, 2011.

3. GUO X., MEI N. Assessment of the toxic potential of graphene family nanomaterials. Journal of Food and Drug Analysis, 22, 105, 2014.

4. HU W., PENG C., LUO W., LV M., LI X., LI D., HUANG Q., FAN C.H. Graphene-based antibacterial paper. ACS Nano, 4, 4317, 2010.

5. Bao, Q., Zhang, D., Qi, P. Synthesis and characterization of silver nanoparticle and graphene oxide nanosheet composites as a bactericidal agent for water disinfection. Journal of Colloid and Interface Science, 360, 463, 2011.

6. GOYAL D., ZHANG X.J., ROONEY-VARGA J.N. Impacts of single-walled carbon nanotubes on microbial community structure in activated sludge. Letters in Applied Microbiology, 51, 428, 2010.

7. SUN J., ZHANG X., MIAO X., ZHOU J. Preparation and characteristics of bioflocculants from excess biological sludge. Bioresource technology, 126, 362, 2012.

8. YUAN S.J., SUN M., SHENG G.P., LI Y., LI W.W., YAO R.S., YU H.Q. Identification of key constituents and structure of the extracellular polymeric substances excreted by bacillus megaterium TF10 for their flocculation capacity. Environmental Science and Technology, 45, 1152, 2011.

9. SURENDHIRAN D., VIJAY M. Exploration on bioflocculation of nannochloropsis oculata using response surface methodology for biodiesel production. The Scientific World Journal, 20, 14 (11), 202659, 2014.

10. SUN J., ZHANG X., MIAO X., ZHOU J. Preparation and characteristics of bioflocculants from excess biological sludge. Bioresource Technology, 126, 362, 2012.

11. YIM J.H., KIM S.J., AHN S.H., LEE H.K. Characterization of a novel bioflocculant, $\mathrm{p}-\mathrm{KG} 03$, from a marine dinoflagellate, Gyrodinium impudicum KG03. Bioresource Technology, 98, 361, 2007.

12. OH H.M., LEE S.J., PARK M.H., KIM H.S., KIM H.C., YOON J.H., KWON G.S., YOON B.D. Harvesting of Chlorella vulgaris using a bioflocculant from Paenibacillus sp. AM49. Biotechnology Letters, 23, 1229, 2001.
13. PAPAZI A., MAKRIDIS P., DIVANACH P. Harvesting Chlorella minutissima using cell coagulants. Journal of Applied Phycology, 22, 349, 2010.

14. BECERRIL H.A., MAO J., LIU Z., STOLTENBERG R. M., BAO Z.N., CHEN Y.S. Evaluation of solution-processed reduced graphene oxide films as transparent conductors. ACS nano, 2 (3), 463, 2008.

15. DIKIN D.A., STANKOVICH S., ZIMNEY E.J. Preparation and characterization of graphene oxide paper. Nature, $\mathbf{4 4 8}$ (7152), 457, 2007.

16. EDA G., FANCHINI G., CHHOWALLA M., Large-area ultrathin films of reduced graphene oxide as a transparent and flexible electronic material. Nature nanotechnology, $\mathbf{3}$ (5), 270, 2008.

17. YOKOI H., ARATAKE T., NISHIO S., HIROSE J., HAYASHI S., TAKASAKI Y. Chitosan production from shochu distillery wastewater by funguses. Journal of Fermentation and Bioengineering, 85, 246, 1998.

18. DENG S., YU G., TING Y.P. Production of a bioflocculant by Aspergillus parasiticus and its application in dye removal. Colloids and Surfaces B: Biointerfaces, 44, 179, 2005.

19. ALJUBOORI A.H.R., IDRIS A., ABDULLAH N., MOHAMAD R. Production and characterization of a bioflocculant produced by Aspergillus flavus. Bioresource Technology 127, 489, 2013.

20. DENG S.B., BAI R.B., HU X.M., LUO Q. Characteristics of a bioflocculant produced by Bacillus mucilaginosus and its use in starch wastewater treatment. Applied Microbiology and Biotechnology, 60, 588, 2003.

21. FUJITA M., IKE M., TACHIBANA S., KITADA G., KIM S.M., INOUE Z. Characterization of a bioflocculant produced by Citrobacter sp. TKF04 from acetic and propionic acids. Journal of Bioscience and Bioengineering, 89, 40, 2000.

22. POORNIMA DEVI T., VIMALA EBENEZER A., ADISH KUMAR S., KALIAPPAN S., RAJESH BANU J. Effect of deflocculation on the efficiency of disperser induced dairy waste activated sludge disintegration and treatment cost. Bioresource Technology, 167, 151, 2014.

23. ZHAO G., LI J., REN X., CHEN C., WANG X. Few-layered graphene oxide nanosheets as superior sorbents for heavy metal ion pollution management. Environmental Science and Technology, 45, 10454, 2011.

24. WANG H., YUAN X., WU Y., HUANG H., ZENG G., LIU Y., WANG X.L., LIN N.B., Q., Y. Adsorption characteristics and behaviors of graphene oxide for $\mathrm{Zn}$ (II) removal from aqueous solution. Applied Surface Science, 279, 432, 2013.

25. MKHOYAN K.A., ALEXANDER W., CONTRYMAN A.W., SILCOX J., STEWART D.A., EDA G., MATTEVI C., MILLER S., CHHOWALLA M. Atomic and electronic structure of graphene-oxide. Nano letters, 9 (3), 1058, 2009.

26. BOUKHVALOV D.W., KATSNELSON M.I. Modeling of graphite oxide. Journal of the American Chemical Society, 130 (32), 10697, 2008.

27. MIRMOHSENI A., SEYED DORRAJI M.S., FIGOLI A., TASSELLI F. Chitosan hollow fibers as effective biosorbent toward dye: Preparation and modeling. Bioresource Technology, 121, 212, 2012.

28. CAO J., WU Y., JIN Y., YILIHAN P., HUANG W. Response surface methodology approach for optimization of the removal of chromium(VI) by NH2-MCM-41. Journal of the Taiwan Institute of Chemical Engineers, 45, 860, 2014.

29. CHAUDHARY N., BALOMAJUMDER C. Optimization study of adsorption parameters for removal of phenol on 
aluminum impregnated fly ash using response surface methodology. Journal of the Taiwan Institute of Chemical Engineers, 45, 852, 2014.

30. LIU Z.M., WANG X.Z., LUO Z., HUO M.Z., WU J.H., HUO H.L., YANG W. Removing of Disinfection ByProduct Precursors from Surface Water by Using Magnetic Graphene Oxide. Plos One, 10 (12), e0143819, 2015.

31. MURTAZA S., SHAH L.A., KHAN J.A., SHAH N.S., NISAR J., KHAN H.M., ZHANG P.Y., KHAN A.R. Efficient photocatalytic degradation of norfloxacin in aqueous media by hydrothermally synthesized immobilized $\mathrm{TiO} 2 / \mathrm{Ti}$ films with exposed facets. The Journal of Physical Chemistry A, 120 (50), 9916, 2016.

32. MURTAZA S., SHAH L.A., KHAN A.M., KHAN R.A., KHAN A.R., KHAN H.M. Decomposition of Clofibric Acid in Aqueous Media by Advance Oxidation Techniques: Kinetics Study and Degradation Pathway. Journal of the Chemical Society of Pakistan, 38 (4), 638, 2016.

33. MURTAZA S., KHAN J.A., SHAH L.A., SHAH N.S., KHAN H.M., REHMAN F., KHAN A.R., KHAN A.M.
Degradation of quinolone antibiotic, norfloxacin, in aqueous solution using gamma-ray irradiation. Environmental Science and Pollution Research, 23 (13), 13155, 2016.

34. JAN N., SAYED M., KHAN F.U., KHAN H.M., IQBAL M., KHAN R.A., ANAS M. Gamma - irradiation induced degradation of diclofenac in aqueous solution: kinetics, role of reactive species and influence of natural water parameters. Journal of Environmental Chemical Engineering, 4 (2), 2573, 2016.

35. MURTAZA S., ISMAIL M., KHAN S., TABASSUM S., KHAN H.M. Degradation of ciprofloxacin in water by advanced oxidation process: kinetics study, influencing parameters and degradation pathways. Environmental technology, 37 (5), 590, 2016.

36. SHAH N.S., KHAN J.A., ALA'A H., SAYED M., KHAN H.M. Gamma radiolytic decomposition of endosulfan in aerated solution: the role of carbonate radical. Environmental Science and Pollution Research, 23 (12), 12362, 2016. 